Published in final edited form as:

Curr Opin Pediatr. 2019 April ; 31(2): 262-266. doi:10.1097/MOP.0000000000000741.

\title{
What is new in electronic-cigarettes research?
}

\author{
Brian P. Jenssen ${ }^{a}$ Karen M. Wilson ${ }^{b}$ \\ aDepartment of Pediatrics, University of Pennsylvania School of Medicine and PolicyLab and the \\ Center for Pediatric Clinical Effectiveness, Children's Hospital of Philadelphia, Philadelphia, \\ Pennsylvania \\ bDepartment of Pediatrics, Icahn School of Medicine at Mount Sinai, New York City, New York, \\ USA
}

\section{Abstract}

Purpose of review-Electronic cigarettes (e-cigarettes) and other vaping devices have seen extraordinary growth in use in the past 10 years, and companies are accelerating their development of new products and marketing efforts. In turn, researchers have increased their efforts to determine how e-cigarettes affect health, how marketing these products impacts adolescents and how the use of e-cigarettes may affect adolescents' use of other tobacco products. Products like Juul were not on the market 2 years ago; thus, frequent updates on the topic are essential.

Recent findings-Studies have begun to demonstrate that users of the newer pod systems are exposed to high levels of nicotine, as well as other chemicals. These products are highly marketed, with a strong emphasis on how adolescents can use them surreptitiously. This is concerning to researchers, and other studies have continued to demonstrate that teens who use e-cigarettes are more likely to go on to use combusted tobacco. Further research has also failed to demonstrate that e-cigarettes are useful for people wishing to quit smoking combusted tobacco.

Summary-E-cigarettes and vaping systems are not safe products and should not be used by adolescents.

\section{Keywords}

adolescents; electronic cigarettes; vaping

\section{EMERGING ELECTRONIC CIGARETTE PRODUCTS}

Electronic cigarettes (e-cigarettes), in general, use an electric impulse to heat a nicotine containing liquid to the point where it aerosolizes but does not burn. The use of e-cigarettes

Correspondence to Brian P. Jenssen, MD, MSHP, Department of Pediatrics, University of Pennsylvania School of Medicine and PolicyLab and the Center for Pediatric Clinical Effectiveness, Children's Hospital of Philadelphia, CHOP Robert's Building, 2716 South Street, Rm 11-201, Philadelphia, PA 19146, USA. Tel: +1 215554 4390; Jenssenb@E-Mail.chop.edu.

Solicited Review.

We confirm that our article has not been published in its current form or a substantially similar form (in print or electronically; including on a website), that it has not been accepted for publication elsewhere, and that it is not under consideration by another publication.

Conflicts of interest

There are no conflicts of interest. 
is called 'Vaping'. It is promoted by the industry as an alternative to smoking; however, studies have not shown that they are effective for smoking cessation. The industry has long used marketing techniques that are appealing to adolescents and young adults, such as cartoons and hyper-sexual imagery. These products are also marketed in a variety of flavors, which are far more appealing to youth than a tobacco-flavored product. The industry has been rapidly innovative, from the cigarette-like products introduced in the early 2000s (Fig. 1) to the 'mods' or modified tank systems (Fig. 2) [1]. Recently, the industry has developed e-cigarette products that are more technologically advanced. These products are designed to look like electronic devices, car fobs, coffee cups, credit cards, mobile phones or even tic-tac boxes [2]. Quite distressing to pediatricians are the vaping devices designed to look like asthma inhalers; versions are used to aerosolize marijuana leaf (PUFFiT), or nicotine (QuickNIC). Companies have also developed low vapor and low odor products specifically to facilitate public use.

The JUUL e-cigarette (Fig. 3) was introduced in 2015; by 2016, reports were emerging about its prevalence of use among adolescents. JUUL pods contain $59 \mathrm{mg} / \mathrm{ml}$ of nicotine, which is a significantly higher concentration than the standard e-cigarette liquid. A study completed in June 2018 found 148000 videos on YouTube when searching on 'JUUL' [2], including 15000 from 'JUUL at school', 1040 from 'JUUL in school bathroom' and 6840 from 'JUUL in class'. A variety of suggested techniques for hiding the aerosol plume includes inhaling more deeply (and increasing nicotine absorption), swallowing the aerosol, exhaling under clothing or into a napkin or paper towel. The study also found YouTube videos detailing how to hide JUUL pods. One video demonstrated the use of a Sharpie marker (Fig. 4) [2].

A recent study evaluated the exposure to nicotine by adolescents who used JUUL and other vape pod systems, using urine samples and teen-reported use of e-cigarettes [ ${ }^{\boldsymbol{}}$ ]. In this sample of 506 teens, ages 12-21 years, 7.7\% were daily pod users; JUUL was the most popular brand $(80 \%)$. Bo (36\%), Phix (18\%) and Suorin $(12 \%)$ were also popular. The preferred flavors were menthol/mint (24\%), fruit (21\%) and candy/desserts (18\%). The median urinary cotinine of exclusive pod users $(N=22)$ in this study was $244.8 \mathrm{ng} / \mathrm{ml}$ - an amount higher than has been reported in studies of exclusive combusted tobacco users [4]. Urinary cotinine varied by the type of pod used: the median urinary cotinine of exclusive JUUL users was $135 \mathrm{ng} / \mathrm{ml}$, compared with $508 \mathrm{ng} / \mathrm{ml}$ for exclusive Bo users and $906 \mathrm{ng} / \mathrm{ml}$ for exclusive Phix users. This study highlights the high levels of nicotine that adolescents are exposed to when they use these vape pod systems.

\section{ADOLESCENT EXPOSURE TO TOXIC CHEMICALS FROM ELECTRONIC- CIGARETTES}

E-cigarettes are promoted as a 'reduced harm' product that leads to far less exposure to toxic chemicals than with combusted cigarettes. However, few studies have examined the actual exposures e-ciga-rette users have. In another study, 67 e-cigarette-only users were evaluated and compared to dual users $(\mathrm{N}=16)$ and nontobacco using controls $(N=20)$. In comparison to the above study, these e-cigarette-only users had a wide range of urinary cotinine levels

Curr Opin Pediatr. Author manuscript; available in PMC 2020 April 01. 
$(0-864 \mathrm{ng} / \mathrm{ml})$, with a median of 0 , suggesting that many users were not exposed to the same degree of nicotine. Further, the study team found that the e-cigarette-only users, compared with controls, had higher levels of the volatile organic compounds (VOCs) acrylonitrile (1.3 vs. Ong/mg), acrolein (254 vs. 193ng/mg), propylene oxide (29 vs. $14 \mathrm{ng} / \mathrm{mg}$ ), acrylamide (67 vs. $42 \mathrm{ng} / \mathrm{mg}$ ) and crotonaldehyde (149 vs. 130ng/mg) [5- Fruit flavor use was also associated with increased levels of acrylonitrile ( $10 \mathrm{vs.} 2 \mathrm{ng} / \mathrm{mg}$ ). Adolescents who used both tobacco and e-cigarettes had VOC levels up to three times higher than those who used only e-cigarettes. This suggests that even in the absence of high nicotine levels in these products, users are exposed to toxic chemicals - chemicals identified as carcinogenic - created by the vaping of the humectant or flavors. Adolescents should never use e-cigarette or vaping products.

\section{ELECTRONIC-CIGARETTE USE AMONG YOUTH AND PROGRESSION TO TRADITIONAL CIGARETTE USE}

In January 2018, the National Academies of Sciences, Engineering, and Medicine (NASEM, formerly known as the Institute of Medicine), with support from the Center for Tobacco Products of the Food and Drug Administration (FDA), published an expert committee report of the scientific evidence about e-cigarettes and public health. The report, titled the Public Health Consequences of E-Cigarettes, provides both an overview and in-depth analysis of the evidence, recommends ways to improve the research and highlights gaps that are priority focus areas for future work [6].

For youth and young adults, there is substantial evidence that e-cigarette use increases the risk of ever using combustible tobacco cigarettes [6,7]. Further, for e-cigarette users who have also ever used combustible tobacco cigarettes, there is moderate evidence that ecigarette use increases the frequency and intensity of subsequent combustible tobacco cigarette smoking [6]. These conclusions are based on substantial evidence from several separate, well-designed, longitudinal studies [8-15]. Adolescents and young adults (aged 14-30) who have used e-cigarettes are 3.6 times more likely to report using cigarettes at follow-up, compared to those who had not, according to a recent meta-analysis [7]. In addition, adolescents who use e-cigarettes appear to have fewer social and behavioral risk factors than conventional cigarette users [10-12,14].

These findings raise significant concern that e-cigarettes have the potential to addict a new generation to nicotine and tobacco, slowing or reversing the decline in adolescent cigarette smoking that has occurred over the past 20 years. Data have begun to influence policy, with the FDA recently acknowledging adolescent e-cigarette use as an epidemic. 'E-cigs have become an almost ubiquitous - and dangerous - trend among teens,' FDA Commissioner Scott Gottlieb, M.D., said in a statement in September 2018. 'The disturbing and accelerating trajectory of use we're seeing in youth, and the resulting path to addiction, must end' [16].

Curr Opin Pediatr. Author manuscript; available in PMC 2020 April 01. 


\section{ELECTRONIC-CIGARETTES FOR SMOKING CESSATION FOR ESTABLISHED SMOKERS}

Health claims that e-cigarettes are effective smoking cessation aids are not currently supported by scientific evidence. According to the NASEM report, there is limited evidence regarding the ability of e-cigarettes to promote smoking cessation [6]. In particular, with a limited number of small, randomized controlled trials, there is insufficient evidence on the effectiveness of e-cigarettes as cessation aids compared with no treatment or to FDAapproved smoking cessation treatments [6]. A more recent large-scale, randomized controlled trial found that the use of free e-cigarettes does not result in higher rates of sustained abstinence than traditional smoking-cessation aids and does not increase abstinence rates among smokers who are also offered information and motivational text messages [17].

The overall evidence from observational trials is mixed [6]. When compared to randomize controlled trials, it is inherently more difficult to draw conclusions about the relationship between cause and effect because of the potential for selection bias and unmeasured confounding. Two systematic reviews that included cohort studies published between 2013 and 2015 in meta-analyses each found a negative association between e-cigarette use and cessation, meaning e-cigarette users have lower rates of successful quitting compared to never e-cigarette users $[18,19]$. The NASEM report identified that more recent prospective longitudinal studies report that daily or very frequent e-cigarette use may be associated with cessation, whereas intermittent use may not [6]. Given the current state of the science, smokers interested in quitting should seek and be referred to evidence-based, safe and effective treatments, including nicotine replacement therapy, behavioral counseling and additional pharmacotherapy [20].

For established smokers, e-cigarettes may reduce health risks for the individual user compared to the risk of continued combustible tobacco use [6]. However, tobacco, when used as intended, causes disease, disability and death [21], and discussions and messaging about individual tobacco products must placed in a larger public health context. Even if ecigarettes themselves pose less risk to the user than other tobacco products, they still represent a significant public health burden in need of further regulation, particularly if they cause more adolescents and adults to begin harmful combustible tobacco use or prevent fewer people from quitting tobacco use [6].

\section{AREAS FOR FURTHER RESEARCH}

The NASEM report closed with a call for action: 'More and better research is needed to help clarify whether e-cigarettes will prove to reduce harm—or induce harm—at the individual and the population levels.' [6] As the e-cigarette market grows, there is continued need for research to inform regulatory standards and understand the effects of use and exposure across the lifespan [6]. Additional research is needed to understand the trajectory of addiction among youth and the progression to combustible tobacco products [22]. Studies are needed to determine whether and, if so, how e-cigarettes may be effective for smoking 
cessation [6]. Finally, research is needed to evaluate effective counter-messaging and public health interventions, especially regarding preventing adolescent e-cigarette initiation.

\section{CONCLUSION}

New research in 2018 is strongly pointing to the potential for e-cigarette products to exposure their users to toxic chemicals, the likelihood of addicting adolescents to nicotine and possible future combusted tobacco use and the continued failure of rigorous studies to show that these products are effective for smoking cessation. The FDA has delayed the implementation of tighter regulations on e-cigarette products, but this year has recognized the dangers of adolescent exposure and targeted companies such as JUUL for their appeal to teens. Pediatricians and other healthcare practitioners that provide care to young adults and adolescents should continue to stress the dangers of using these products to patients and their parents as well as advocate for restrictions on the purchase and use of these products by teens.

\section{Acknowledgements}

Financial support and sponsorship

None.

\section{REFERENCES AND RECOMMENDED READING}

Papers of particular interest, published within the annual period of review, have been highlighted as:

of special interest

[ of outstanding interest

1. Barrington-Trimis JL, Gibson LA, Halpern-Felsher B, et al. Type of e-cigarette device used among adolescents and young adults: findings from a pooled analysis of eight studies of 2166 vapers. Nicotine Tob Res 2018; 20:271-274. [PubMed: 28371890]

2 . Ramamurthi D, Chau C, Jackler RK. JUUL and other stealth vaporisers: hiding the habit from parents and teachers. Tob Control 2018.This article highlights the myriad ways that e-cigarettes and pod systems are being promoted for use by adolescents.

3 . Goniewicz ML, Boykan R, Messina CR, et al. High exposure to nicotine among adolescents who use Juul and other vape pod systems ('pods'). Tob Control 2018.This article assesses exposure to nicotine by adolescents using vape pod systems.

4. Benowitz NL, Nardone N, Jain S, et al. Comparison of urine 4-(methylnitrosamino)-1-(3)pyridyl-1butanol and cotinine for assessment of active and passive smoke exposure in urban adolescents.

Cancer Epidemiol Biomark Prev 2018; 27:254-261.

5 . Rubinstein ML, Delucchi K, Benowitz NL, Ramo DE. Adolescent exposure to toxic volatile organic chemicals from e-cigarettes. Pediatrics 2018; 141.This article assesses adolescents' exposure to volatile organic chemicals from e-cigarettes.

6 ㅁ. National Academies of Sciences, Engineering, and Medicine Public Health Consequences of ECigarettes. Washington, DC: The National Academies Press; 2018.This article is the expert committee report of the scientific evidence about e-cigarettes and public health.

7. Soneji S, Barrington-Trimis JL, Wills TA, et al. Association between initial use of e-cigarettes and subsequent cigarette smoking among adolescents and young adults: a systematic review and metaanalysis. JAMA Pediatr 2017; 171:788-797. [PubMed: 28654986] 
8. Primack BA, Soneji S, Stoolmiller M, et al. Progression to traditional cigarette smoking after electronic cigarette use among US adolescents and young adults. JAMA Pediatr 2015; 169:10181023. [PubMed: 26348249]

9. Miech R, Patrick ME, O'Malley PM, Johnston LD. E-cigarette use as a predictor of cigarette smoking: results from a 1-year follow-up of a national sample of 12 th grade students. Tob Control 2017; 26:e106-e111. [PubMed: 28167683]

10. Barrington-Trimis JL, Urman R, Berhane K, et al. E-cigarettes and future cigarette use. Pediatrics 2016; 138. [PubMed: 27544347]

11. Leventhal AM, Strong DR, Kirkpatrick MG, et al. Association of electronic cigarette use with initiation of combustible tobacco product smoking in early adolescence. JAMA 2015; 314:700707. [PubMed: 26284721]

12. Wills TA, Knight R, Sargent JD, et al. Longitudinal study of e-cigarette use and onset of cigarette smoking among high school students in Hawaii. Tob Control 2017; 26:34-39. [PubMed: 26811353]

13. Bold KW, Kong G, Camenga DR, et al. Trajectories of E-cigarette and conventional cigarette use among youth. Pediatrics 2018; 141.

14. Watkins SL, Glantz SA, Chaffee BW. Association of noncigarette tobacco product use with future cigarette smoking among youth in the Population Assessment of Tobacco and Health (PATH) study, 2013-2015. JAMA Pediatr 2018; 172:181-187. [PubMed: 29297010]

15. Chaffee BW, Watkins SL, Glantz SA. Electronic cigarette use and progression from experimentation to established smoking. Pediatrics 2018; 141.

16. Commissioner Officer. Press Announcements - Statement from FDA Commissioner Scott Gottlieb, M.D., on new steps to address epidemic of youth e-cigarette use [Internet]. Accessed 27 September, 2018. Available from: https://www.fda.gov/NewsEvents/Newsroom/ PressAnnouncements/ucm620185.htm?utm_campaign=09122018_Statement_FDA\%20statement $\% 20$ on $\% 20$ addressing $\% 20$ epidemic $\% 20$ of\%20youth $\% 20$ e-cigarette $\% 20$ use \&utm_medium=EMail\&utm_source=Eloqua.

17. Halpern SD, Harhay MO, Saulsgiver K, et al. A pragmatic trial of e-cigarettes, incentives, and drugs for smoking cessation. N Engl J Med 2018; 378:2302-2310. [PubMed: 29791259]

18. Kalkhoran S, Glantz SA. E-cigarettes and smoking cessation in real-world and clinical settings: a systematic review and meta-analysis. Lancet Respir Med 2016; 4:116-128. [PubMed: 26776875]

19. El Dib R, Suzumura EA, Akl EA, et al. Electronic nicotine delivery systems and/or electronic nonnicotine delivery systems for tobacco smoking cessation or reduction: a systematic review and meta-analysis. BMJ Open 2017; 7:e012680.

20. Fiore MC, Jaén CR, Baker TB, et al. Treating Tobacco Use and Dependence: 2008 Update. Clinical Practice Guideline. Rockville, MD: U.S. Department of Health and Human Services. Public Health Service; 2008.

21. U.S. Department of Health and Human Services. The Health Consequences of Smoking-50 Years of Progress: A Report of the Surgeon General, 2014 [Internet] Atlanta, GA: U.S. Department of Health and Human Services, Centers for Disease Control and Prevention, National Center for Chronic Disease Prevention and Health Promotion, Office on Smoking and Health; 2014.

22. U.S. Department of Health and Human Services. E-Cigarette Use Among Youth and Young Adults. A Report of the Surgeon General Atlanta, GA: U.S. Department of Health and Human Services, Centers for Disease Control and Prevention, National Center for Chronic Disease Prevention and Health Promotion, Office on Smoking and Health; 2016. 


\section{KEY POINTS}

- $\quad$ Recent evidence highlights the high levels of nicotine that adolescents are exposed to when they use vape pod system e-cigarettes, such as JUUL.

- Even in the absence of high nicotine levels in these products, users are exposed to toxic chemicals - chemicals identified as carcinogenic - created by the vaping of the humectant or flavors.

- For youth and young adults, there is substantial evidence that e-cigarette use increases the risk of ever using combustible tobacco cigarettes.

- According to the National Academy of Science report on the public health consequences of e-cigarettes, there is limited evidence regarding the ability of e-cigarettes to promote smoking cessation.

- Pediatricians and other healthcare practitioners that provide care to young adults and adolescents should continue to stress the dangers of using these products to patients and their parents as well as advocate for restrictions on the purchase and use of these products by teens. 


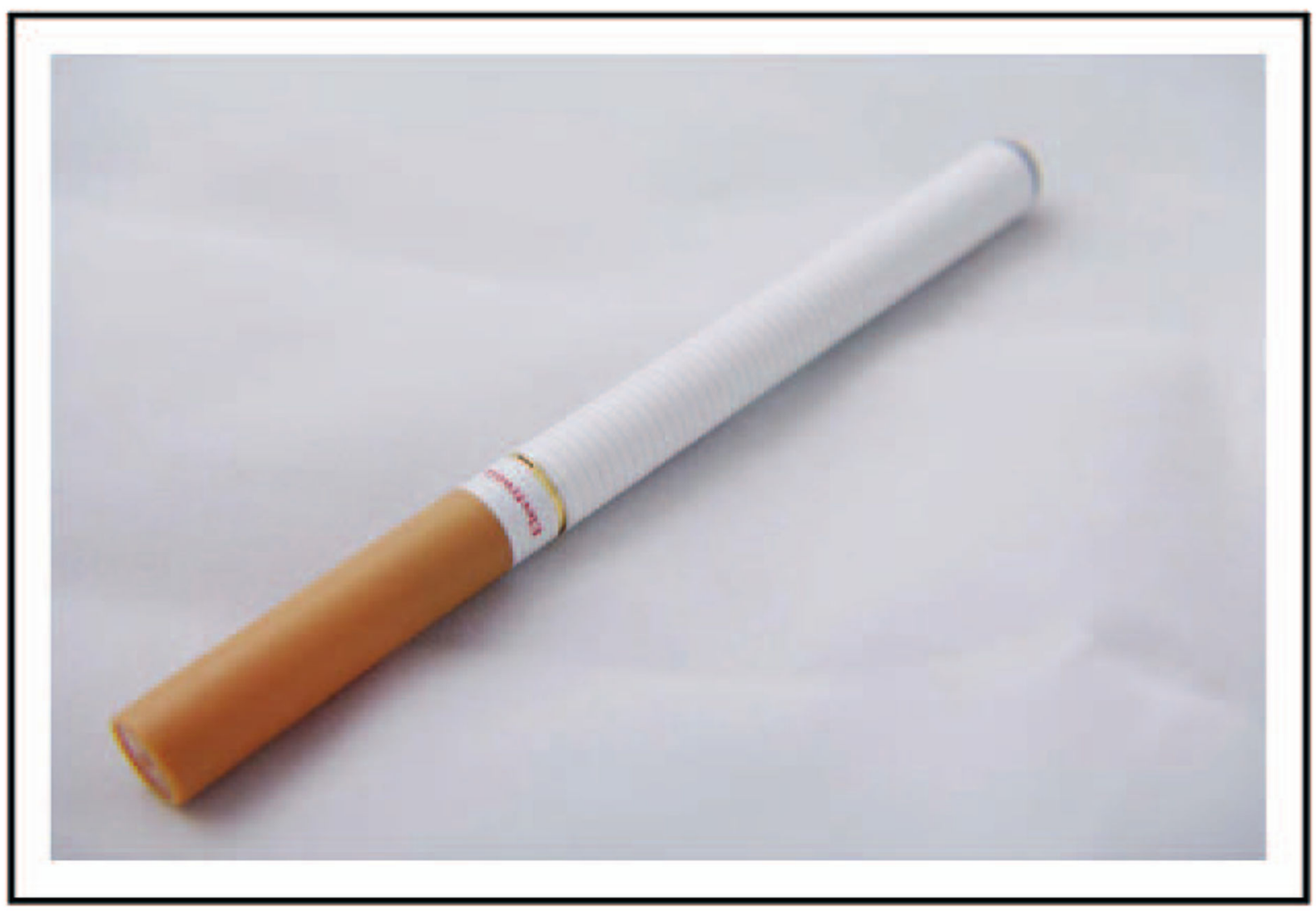

FIGURE 1.

First generation e-cigarette. 


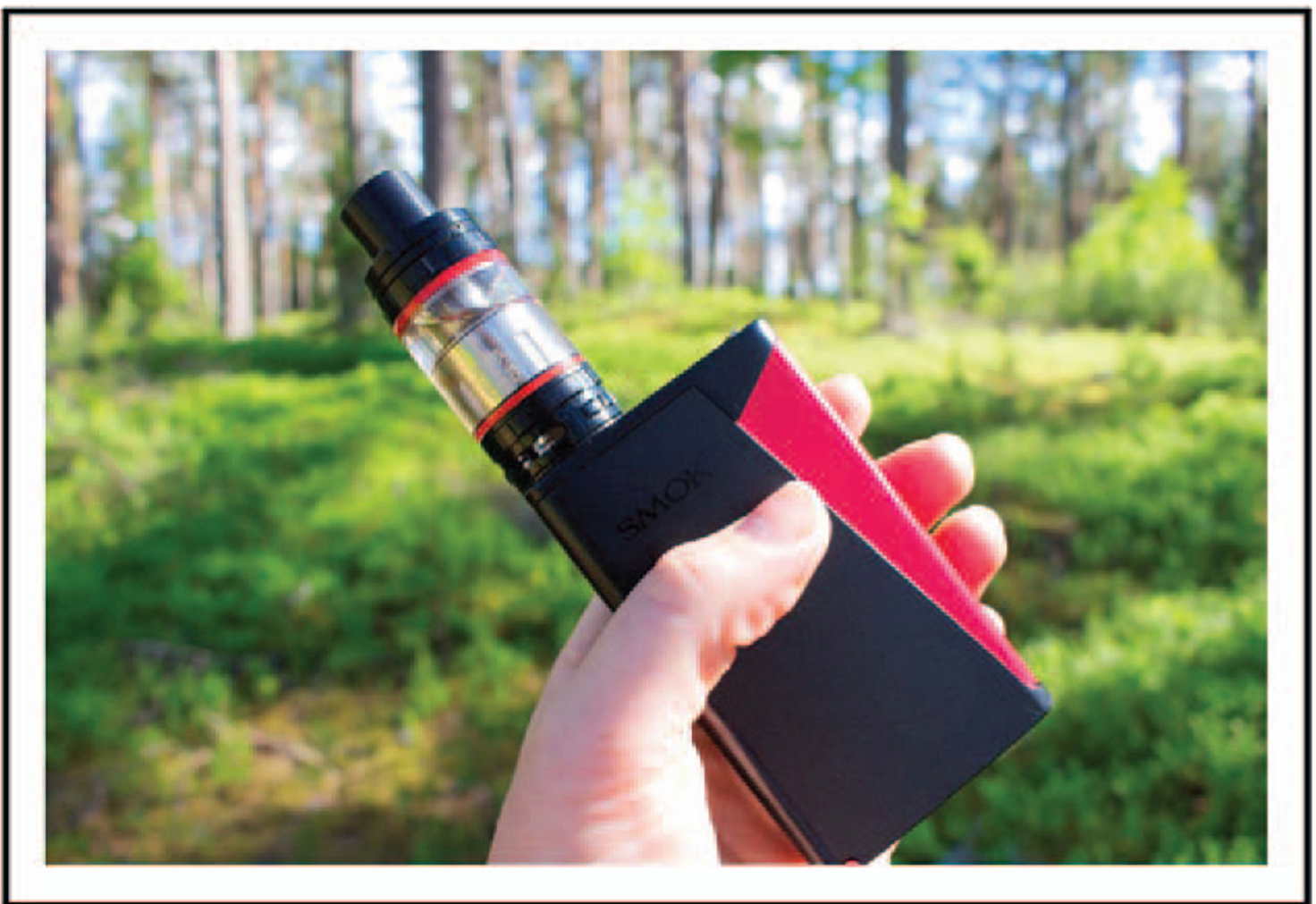

FIGURE 2.

Tank system or 'Mod'.

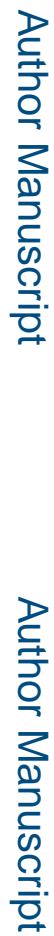




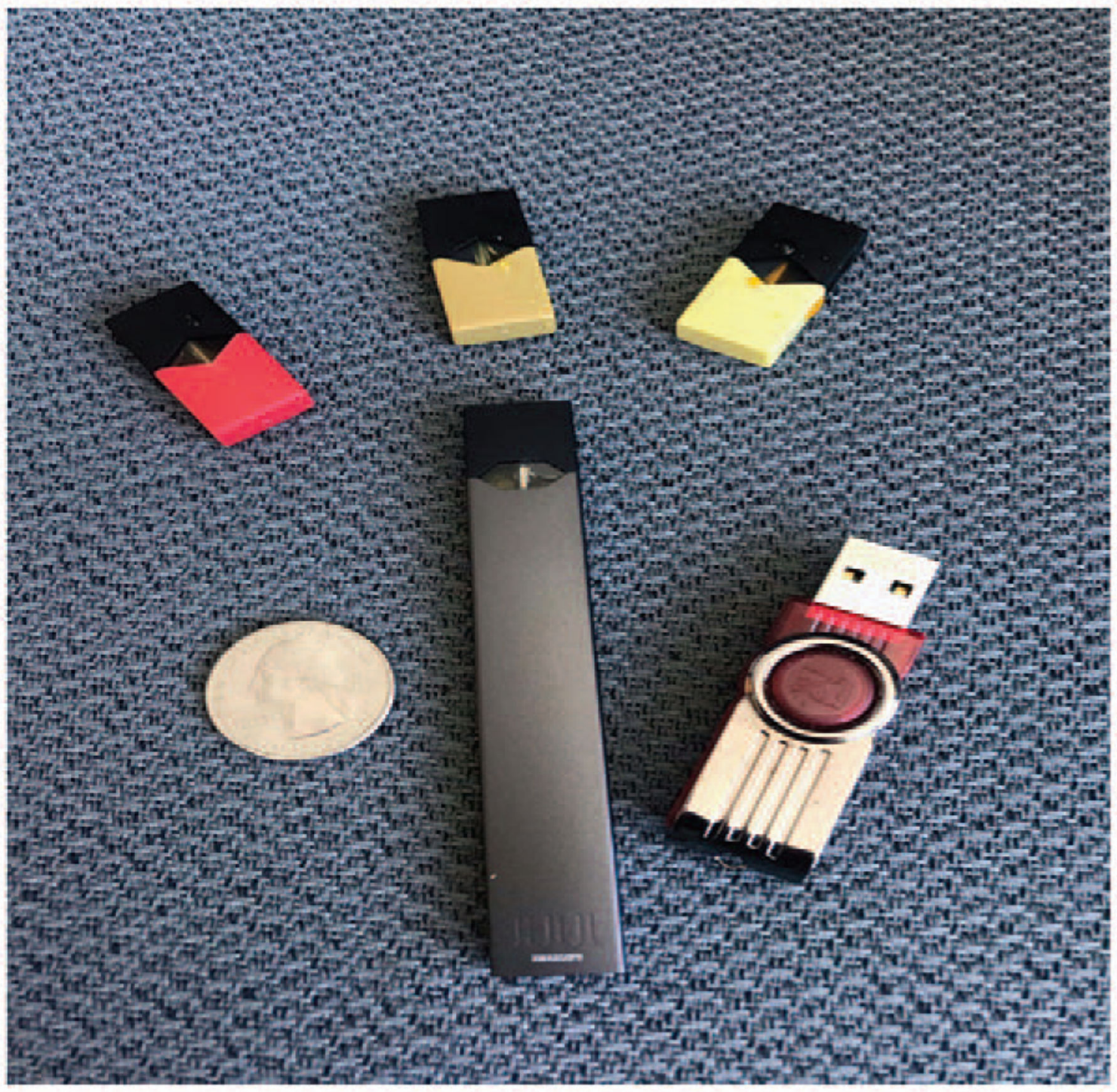

FIGURE 3.

JUUL with pods. Permission: Susanne Tanski, MD, MPH.

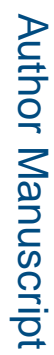




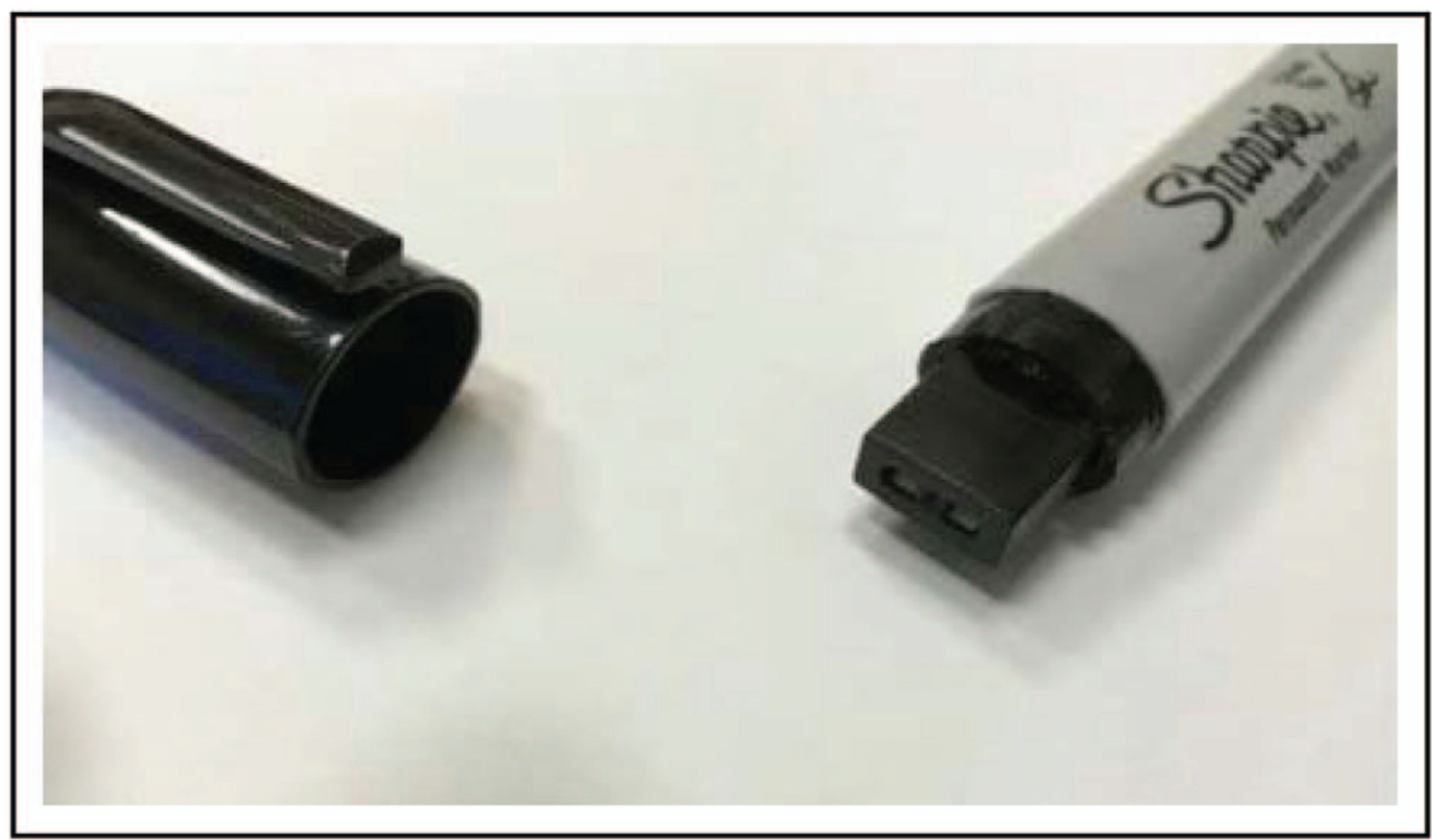

FIGURE 4.

Hiding JUUL in a Sharpie. Source: Ramamurthy et al. [2]. 